\title{
Testing of the impact of dielectric thickness on basic parameters of the microstrip GSM / LTE antenna
}

Jaroslaw Bugaj, Krystian Łata

Jaroslaw Bugaj, Krystian Łata, "Testing of the impact of dielectric thickness on basic parameters of the microstrip GSM / LTE antenna," Proc. SPIE 11442, Radioelectronic Systems Conference 2019, 114420P (11 February 2020); doi: $10.1117 / 12.2565058$

SPIE. Event: Radioelectronic Systems Conference 2019, 2019, Jachranka, Poland 


\title{
Testing of the impact of dielectric thickness on basic parameters of the microstrip GSM / LTE antenna
}

\author{
Jarosław Bugaj*a Krystian Łata ${ }^{a}$ \\ ${ }^{a}$ Military University of Technology, Faculty of Electronics,00-908 Warsaw, Gen. S. Kaliskiego 2. st.
}

\begin{abstract}
The article presents the model of a dual-band LTE antenna operating on the $1800 \mathrm{MHz}$ and $2600 \mathrm{MHz}$ band as well as the results of research on the influence of antenna dielectric thickness on selected parameters. Designed and the built antenna works in the 1.71-1.93 GHz frequency band for GSM 1800, GSM 1900 and $2.42-2.85 \mathrm{GHz}$ frequency for LTE 2500, LTE 2600. Using the transmission line model, the antenna dimensions were obtained and then in the CST Studio Suite environment, the presented parameters were obtained by means of optimization. The parameters obtained before and after the dielectric thickness change were compared with each other. The practically made antenna was tested in the Electromagnetic Compatibility Laboratory of the Military University of Technology.
\end{abstract}

Keywords: antenna LTE, dielectric thickness, dual band antenna, microstrip antenna, LTE, GSM.

\section{INTRODUCTION}

Nowadays, one antenna should work in GSM, UMTS and LTE technologies. That is why it is required from telecommunication service providers to develop multi-range antennas. The antenna, which is an inseparable part of portable telecommunications devices, should be characterized by low weight, small size and wide bandwidth. In the practical design of mobile devices, antennas had limited space, especially a small thickness device like laptops, tablets, mobile phones and USB modems. Usually thickness is a range from 5 to 12 millimeters. Antennas, which are characterized by small size, low profile and the ability to work in many frequency bands are the planar antennas. The article presents the model of a dual-band LTE antenna operating on the $1800 \mathrm{MHz}$ and $2600 \mathrm{MHz}$ band and results of the impact of antenna dielectric thickness on selected parameters. LTE technology is revolutionizing the world by providing the fastest data transmission. It is a radical step forward for the wireless industry. The main goal of LTE is to provide a highly efficient, low latency and a safer service. This new system include OFDM (Orthogonal Frequency Division Multiplexing) to avoid interfering signals between symbols that typically limit the performance of high speed systems and MIMO (Multiple-Input Multiple-Output) techniques to increase speed data transmission. The designed and constructed antenna cover the 1.71- $1.93 \mathrm{GHz}$ frequency band for GSM 1800, GSM 1900 and $2.42-2.85 \mathrm{GHz}$ for technology LTE 2500, LTE 2600. Using transmission line model, the initial antenna dimensions have been calculated. Flowingly by using optimization in CST Studio Suite environment, the presented parameters were obtained. Article presents parameters before and after changes of dielectric thickness and their comparison. The physical antenna was tested in the Electromagnetic Compatibility Laboratory of the Military University of Technology. The designed antenna model is a microstrip antenna operating in two bands used in Europe in the LTE standard, i.e. $1800 \mathrm{MHz}$ and $2600 \mathrm{MHz}^{1,4,5}$.

The basic dimensions of the radiator of the microstrip antenna were calculated from the dependence (1) - width and (2) length ${ }^{2,7}$.

Where:

$$
\begin{aligned}
& W=\frac{c}{2 f_{r} \sqrt{\frac{e_{r}+1}{2}}} \\
& L=L_{e f f}-2 * \Delta L
\end{aligned}
$$

$$
L_{e f f}=\frac{c}{2 f_{r} \sqrt{\epsilon_{e f f}}}
$$

*jaroslaw.bugaj@wat.edu.pl; phone +48 261839 906; wel.wat.edu.pl

Radioelectronic Systems Conference 2019, edited by Piotr Kaniewski, Jan Matuszewski, Proc. of SPIE Vol. 11442, 114420P · (c) 2020 SPIE · CCC code: 0277-786X/20/\$21 · doi: 10.1117/12.2565058 


$$
\begin{gathered}
\Delta L=0.412 \frac{\left(\epsilon_{e f f}+0.3\right)\left(\frac{W}{h}+0.264\right)}{\left(\epsilon_{e f f}-0.264\right)\left(\frac{W}{h}+0.8\right)} \\
\epsilon_{e f f}=\frac{\epsilon_{r}+1}{2}+\frac{\epsilon_{r}-1}{2}\left[1+12 \frac{h}{W}\right]^{\frac{1}{2}}
\end{gathered}
$$

The dimensions of the designed antenna were optimized by using the CST Studio Suite environment. Additionally, the main parameters for the selected dielectric thickness were calculated numbers. It should be in a one-column format. References are often noted in the text ${ }^{1}$ and cited at the end of the paper.

\section{ANTENNAS CONSTRUCTION}

If the paper does not have the margins shown in Table 1, it will not upload properly. Fig. 1 shown construction of the dual-band antenna LTE. It is a microstrip antenna, powered by a microstrip line with a SMA female connector with 50 Ohm impedance. It was made on a FR-4 substrate from ROGERS CORPORATION with a size of $192 \mathrm{x} 129 \mathrm{~mm}$, dielectric thickness of $\mathrm{t}=1.5 \mathrm{~mm}$ and a relative permittivity $\epsilon_{\mathrm{r}}=4.6$. The designed antenna was made practically and tested in the Electromagnetic Compatibility Laboratory of the Military University of Technology. Realized the antenna design presented in Figure 1, the assumptions presented in Table 1 were adopted.

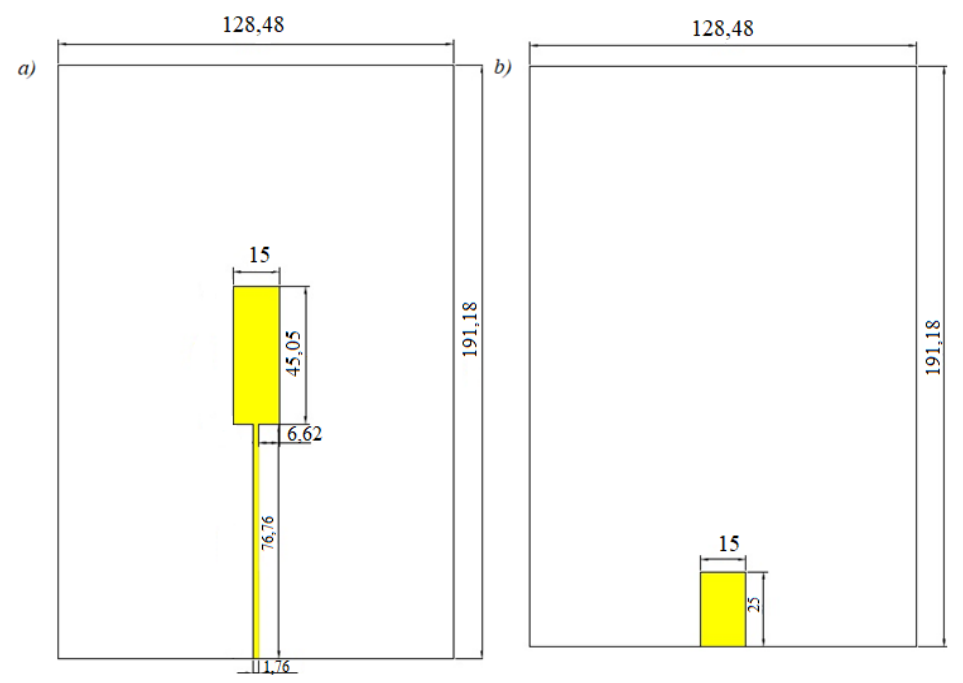

Figure 1. Antenna construction: a) view from the side of the radiator b) view from the side of the screen.

Table 1. Design assumptions.

\begin{tabular}{|lrrrrr}
\hline \multicolumn{5}{|c|}{ Design assumptions } \\
Assumptions & \multicolumn{4}{c|}{ Assumptions } \\
\cline { 5 - 6 } Frequency & $1800,2600 \mathrm{MHz}$ & & Dielectric thickness & $1.5 \mathrm{~mm}$ \\
Substrat & $\mathrm{FR}-4($ loss free) & & Dielectric loss factor $t g \delta$ & 0.02 \\
Relative permittivity & $\varepsilon_{\mathrm{r}}$ & 4.6 & & Feed & Microstrip Line \\
VSWR & $\leq 2$ & & $\mathrm{~S}_{11}$ & $\leq-10 \mathrm{~dB}$ \\
\hline
\end{tabular}

\section{SIMULATION RESULTS}

During change the thickness of the dielectric in CST Studio Suite environment the following parameters of designed antenna has been analyzed: S11 reflection coefficient, VSWR, input impedance and gain. 


\section{1 $S_{11}$ reflection coefficient}

Figure 2 presents the results obtained during computer simulation in the CST Studio Suite environment. As you can see, when the thickness of the dielectric increases, the width of the operating band decreases and the center frequencies shift towards the lower frequencies. In the case of reducing the dielectric thickness the situation is reversed - with the decreasing of the dielectric thickness, the operating band becomes wider, and the center frequencies shift towards higher frequencies.

For the smallest thickness of the dielectric, i.e. $\mathrm{t}=1 \mathrm{~mm}$ bandwidth $f_{0}=1.8 \mathrm{GHz}$ increased from $196 \mathrm{MHz}$ to $530 \mathrm{MHz}$, and for $f_{0}=2.6 \mathrm{GHz}$ increased from $433 \mathrm{MHz}$ to $800 \mathrm{MHz}$. Which means that the bands have almost doubled. While the center frequency shifted to the right sequentially from $f_{0}=1.8 \mathrm{GHz}$ to $f_{0} \approx 1,9 \mathrm{GHz}$ and from $f_{0}=2.6 \mathrm{GHz}$ to $f_{0} \approx 2,9 \mathrm{GHz}$. For the largest thickness of the dielectric, i.e. $\mathrm{t}=2 \mathrm{~mm}$ band was reduced from $223 \mathrm{MHz}$ to $202 \mathrm{MHz}$, and for $f_{0}=2.6 \mathrm{GHz}$ decreased from $433 \mathrm{MHz}$ to $330 \mathrm{MHz}$. By contrast, the center frequencies shifted sequentially left from $f_{0}=1.8 \mathrm{GHz}$ to $f_{0} \approx 1,7 \mathrm{GHz}$ and from $f_{0}=2.6 \mathrm{GHz}$ to $f_{0} \approx 2,5 \mathrm{GHz}$. Of course, the best results remain at the initial thickness of the dielectric, $\mathrm{t}=1.5 \mathrm{~mm}$.

a)

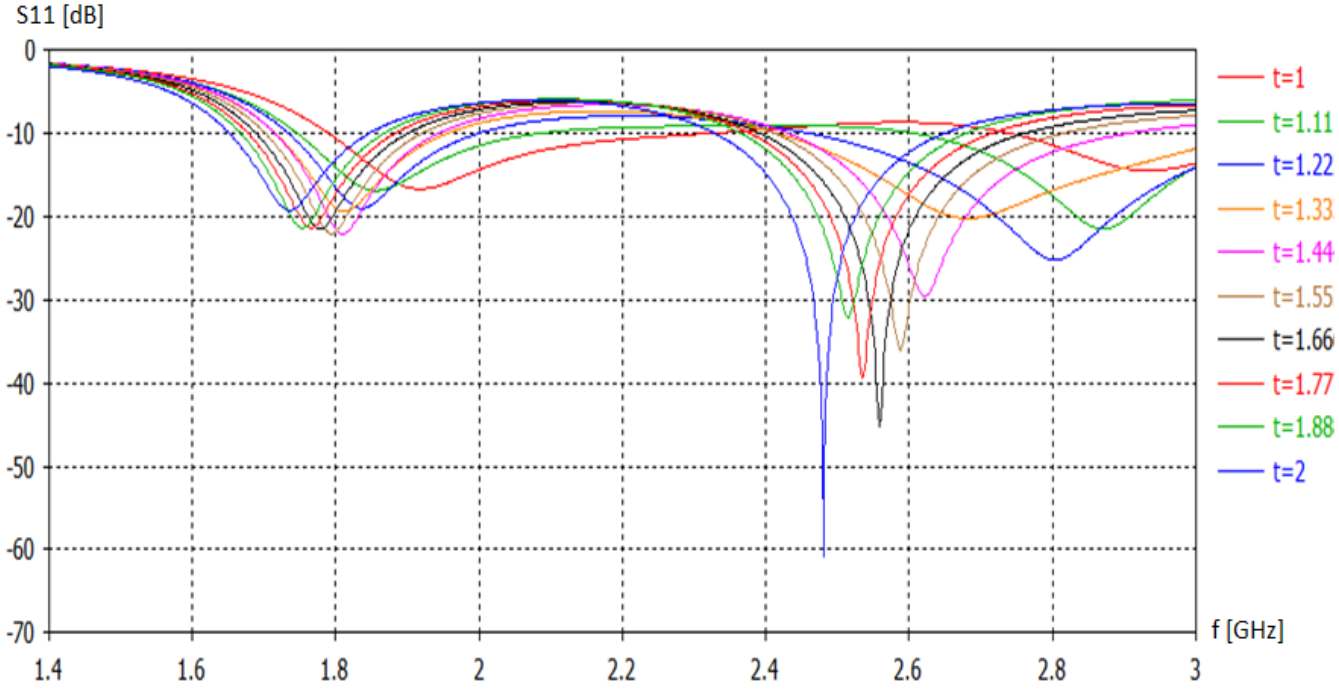

b)

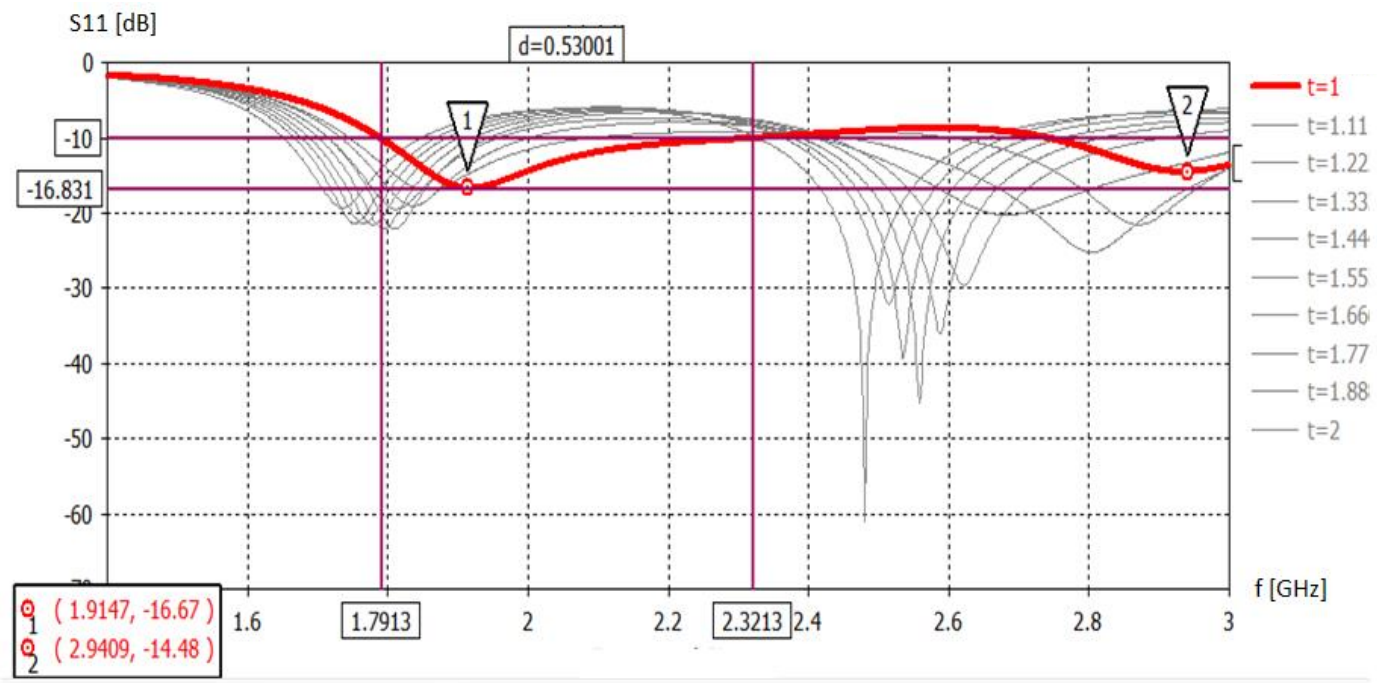


c)

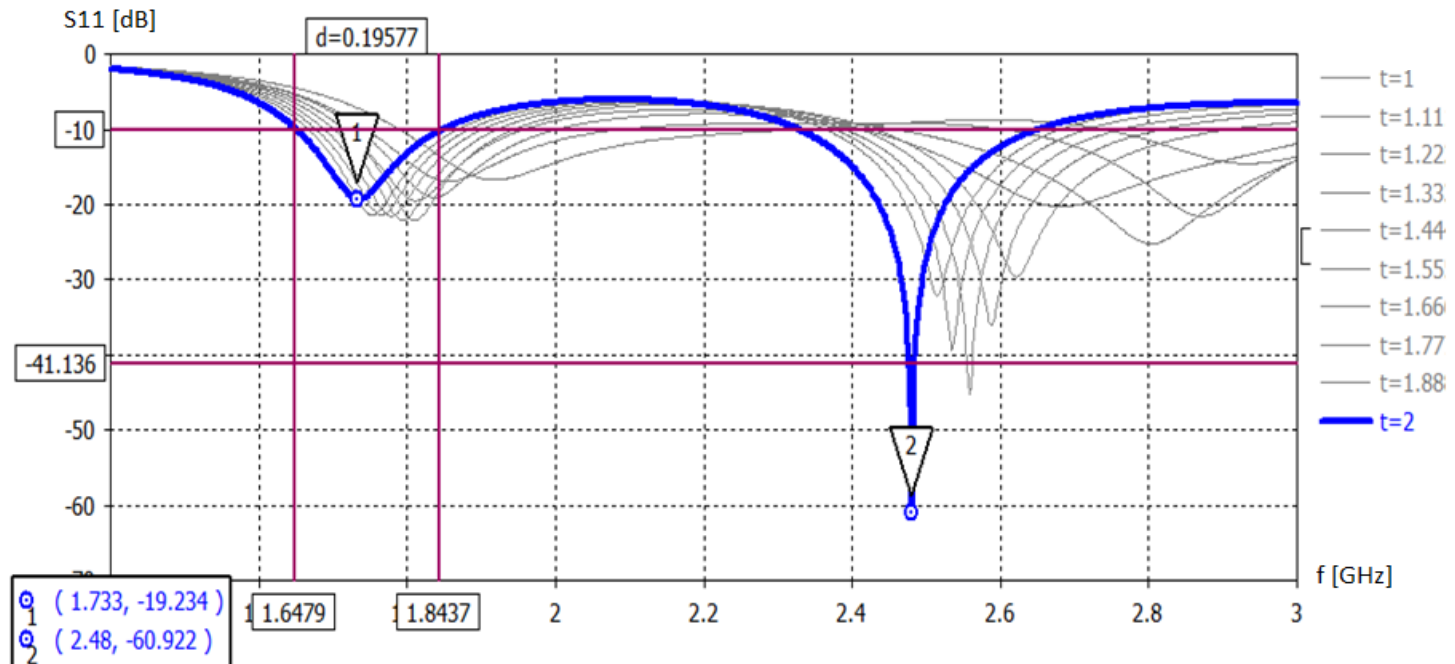

Figure 2. The effect of the dielectric thickness on the reflection coefficient $\mathrm{S}_{11}$ for selected thicknesses $\mathrm{t}[\mathrm{mm}]$ : a) $\mathrm{t}=1-2[\mathrm{~mm}]$, b) $\mathrm{t}=1[\mathrm{~mm}]$ : c) $\mathrm{t}=2[\mathrm{~mm}]$.

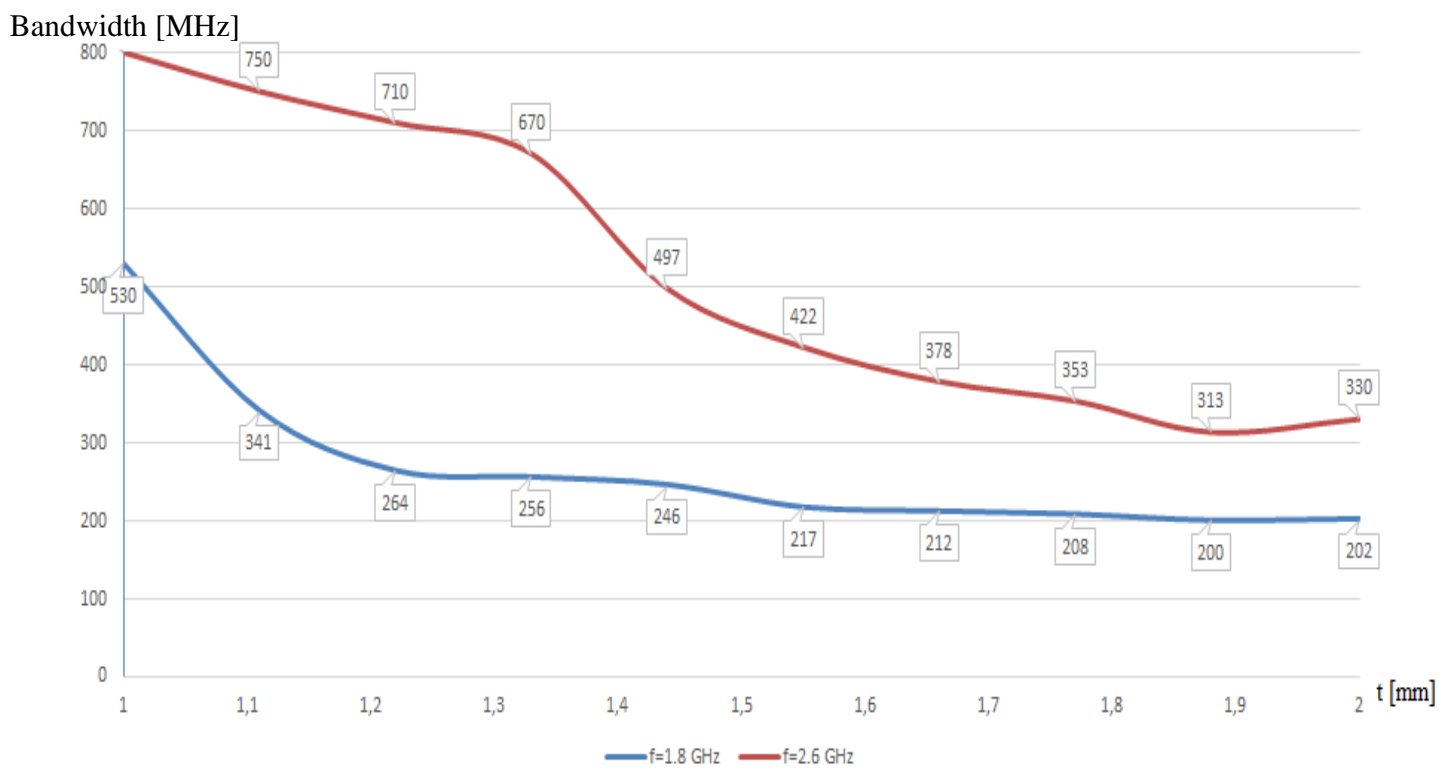

Figure 3. Influence of dielectric thickness on the antenna bandwidth.

\subsection{Input impedance}

Figure 4 presents the results how the dielectric thickness influence on the input impedance obtained during computer simulation in the CST Studio Suite environment. When the thickness of the substrate decreases, the real part of the input impedance decreases. The best result for both ranges is for the initial thickness, i.e. $t=1.5 \mathrm{~mm}$. However, for the center frequency $f_{0}=2.6 \mathrm{GHz}$ beginning from the ground thickness $\mathrm{t}=1.33 \mathrm{~mm}$, the value of $R_{w e}$ oscillates around $50 \Omega$. For the center frequency $f_{0}=1.8 \mathrm{GHz}$ the best level of $R_{w e}$ is for the initial thickness. This means that the antenna could be used for the center frequency $f_{0}=2.6 \mathrm{GHz}$ with a higher dielectric thickness while for $f_{0}=1.8 \mathrm{GHz}$ antenna would not work properly because of some noise and interference.

For the imaginary part $Z_{\mathrm{we}}$ the situation is reversed. When thickness of the substrate decreases, the imaginary part of the input impedance grows, whereas with the increase of the dielectric thickness the imaginary part of the input impedance 
decreases. The best result for both ranges is for the output thickness, i.e. $\mathrm{t}=1.5 \mathrm{~mm}$. In this case, better level of $Z_{\mathrm{we}}$ is for frequency $f_{0}=1.8 \mathrm{GHz}$. From the ground thickness $\mathrm{t}=1.5 \mathrm{~mm}$, the value $j X_{w e}$ oscillates within $0 \Omega$. The best result is for the dielectric thickness $\mathrm{t}=1.77 \mathrm{~mm}$ where the $-j X_{w e}=0.95 \Omega$. For the frequency $f_{0}=2.6 \mathrm{GHz}$, the best values of $j X_{w e}$ oscillates around initial substrate thickness. To improve the antenna work on both frequencies when the dielectric thickness is changed, we can place a tuner to the power line, which will get a better matching.
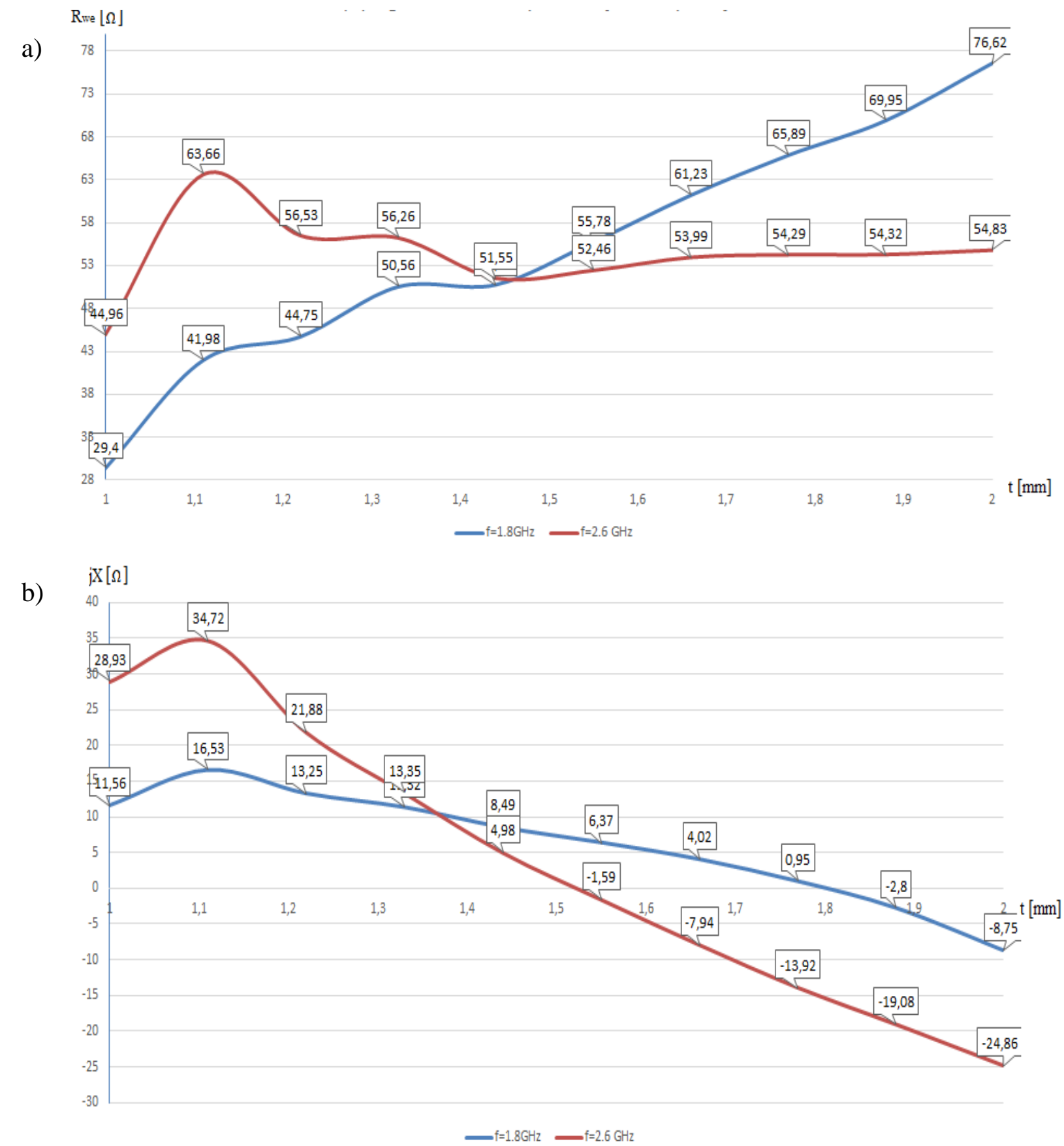

Figure 4. List of characteristics of dielectric thickness influence on input impedance for $f_{0}=1.8 \mathrm{GHz}$ and $f_{0}=2.6 \mathrm{GHz}$ : a) real part b) imaginary part. 


\subsection{Gain}

Figure 5 presents the results how the dielectric thickness influence on gain obtained during computer simulation in the CST Studio Suite environment. With the reduction of the thickness of the substrate, the gain decreases and with the increase of the dielectric thickness the gain grows. The lower frequency $f_{0}=1.8 \mathrm{GHz}$ let to more noticeable this increase. The value of gain changed from $G=3.65 \mathrm{~dB}$ to $G=3.83 \mathrm{~dB}$. In the case of the higher frequency $f_{0}=2.6 \mathrm{GHz}$, this change is smaller, however, there is also an increase from $G=4.27 \mathrm{~dB}$ to $G=4.33 \mathrm{~dB}$. Therefore, with the increase of the dielectric thickness, the efficiency of the antenna grows. It means that most of the power supplied at its input terminals is converted into energy which is radiated into space with including its directional properties.

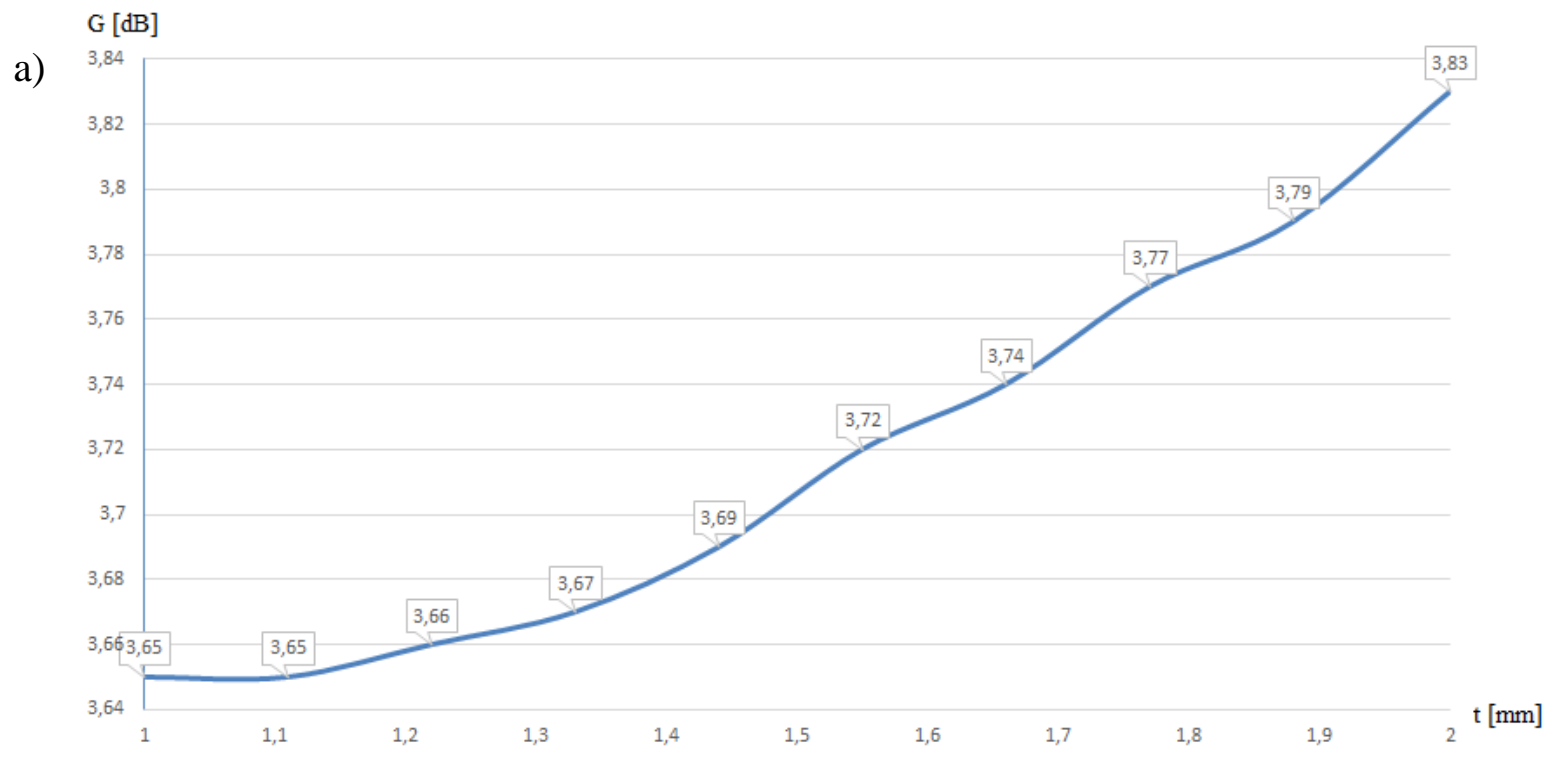

b) G $[\mathrm{dB}]$

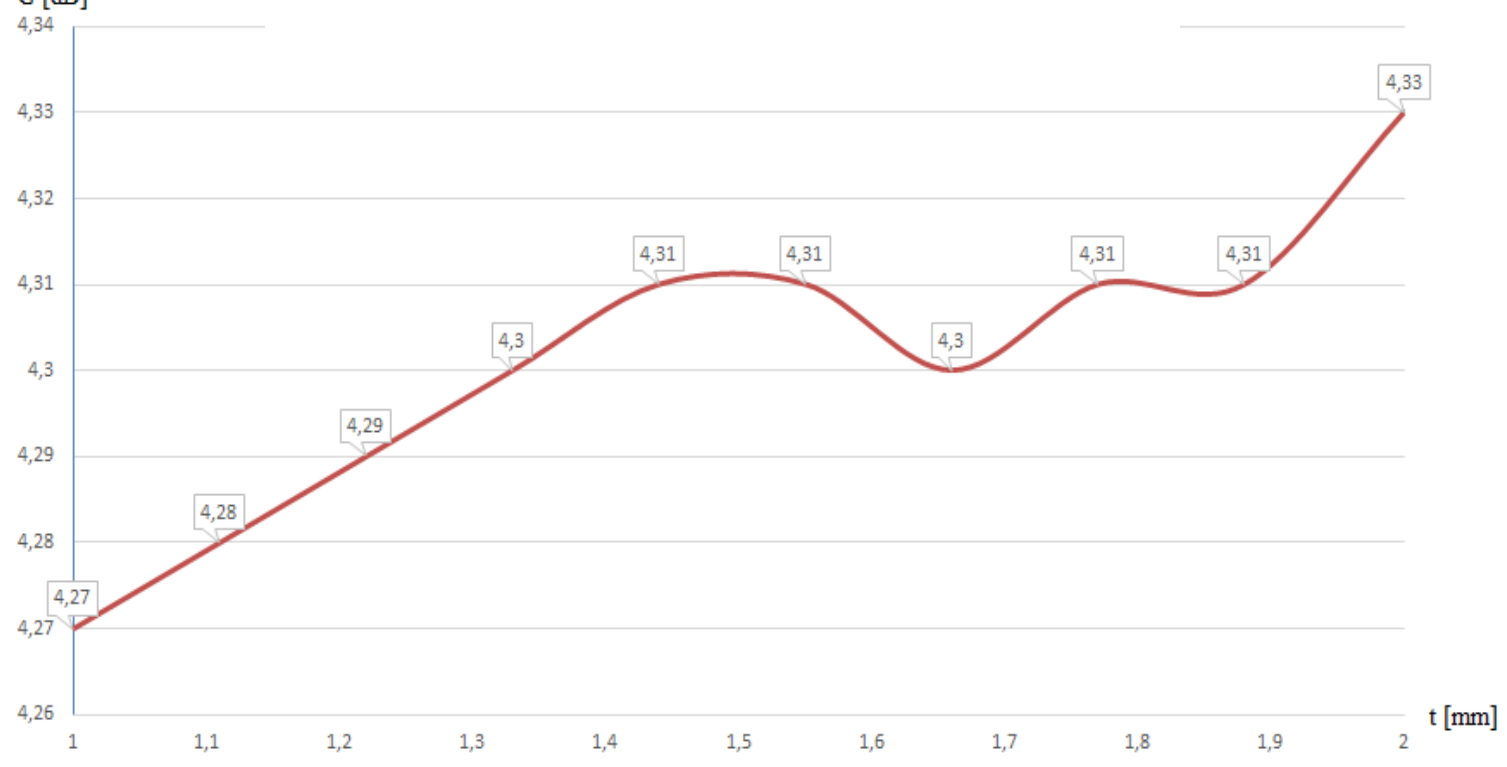

Figure 5. List of characteristics of dielectric thickness influence on on gain for $f_{0}=1.8 \mathrm{GHz}$ and $f_{0}=2.6 \mathrm{GHz}$ : a) real part b) imaginary part. 


\section{ANALYSIS OF PRACTICALLY OBTAINED RESULTS}

The antenna designed and described in this article was physically made and research at the Faculty of Electronics of the Military University of Technology in the Laboratory of Electromagnetic Compatibility.

The band obtained during computer simulations for VSWR $<2$ marginally differ from the results obtained during laboratory tests. Respectively for the range:

- $\quad 1.8 \mathrm{GHz}$, the band during the simulation was $1.70 \mathrm{GHz}-1.94 \mathrm{GHz}$ and for the physical antenna: $1.78 \mathrm{GHz}$ to $2.11 \mathrm{GHz}$. However, the values at $1.82 \mathrm{GHz}$ to $1.99 \mathrm{GHz}$ oscillate almost at WFS $=2$,

- $\quad 2.6 \mathrm{GHz}$, the band during the simulation was $2.41 \mathrm{GHz}-2.88 \mathrm{GHz}$ while after testing in the laboratory $2.24 \mathrm{GHz}$ to $2.81 \mathrm{GHz}$. The band has expanded by $10 \mathrm{MHz}$.

a)

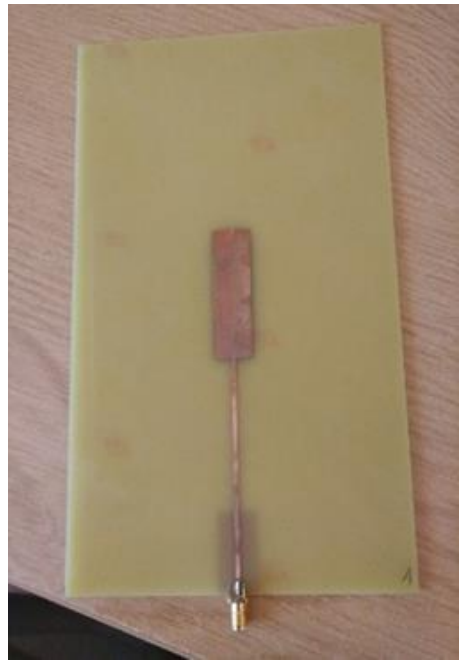

b)

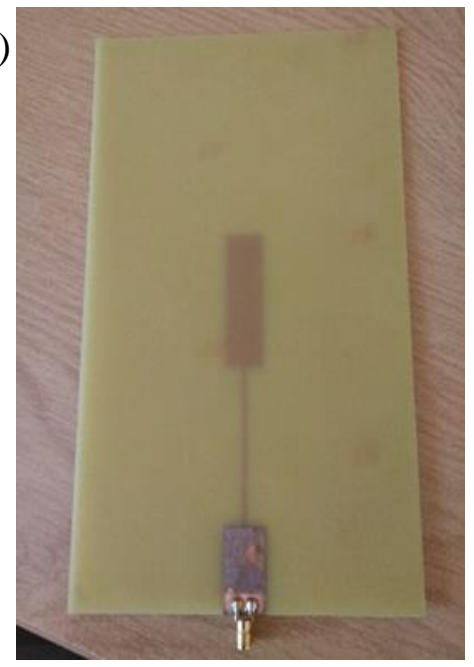

c)

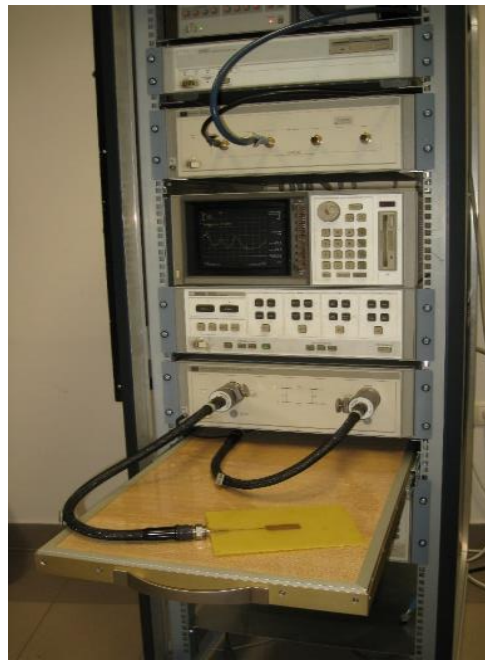

Figure 6. The model of the physically constructed antenna: a) the view from the side of the radiator, b) the view from the side of the screen, c) the physical model of the tested antenna on the measurement stand in the WAT Laboratory of Electromagnetic Compatibility.

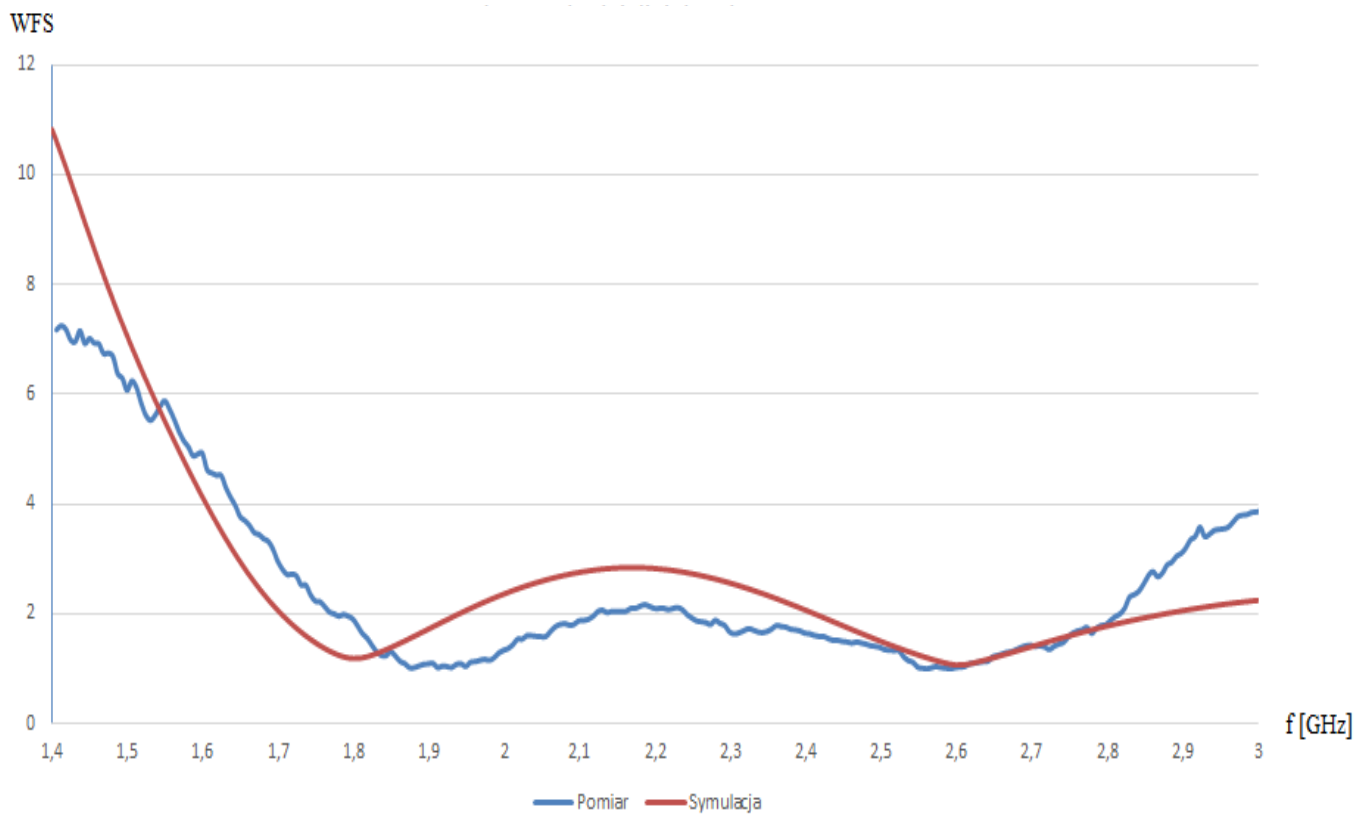




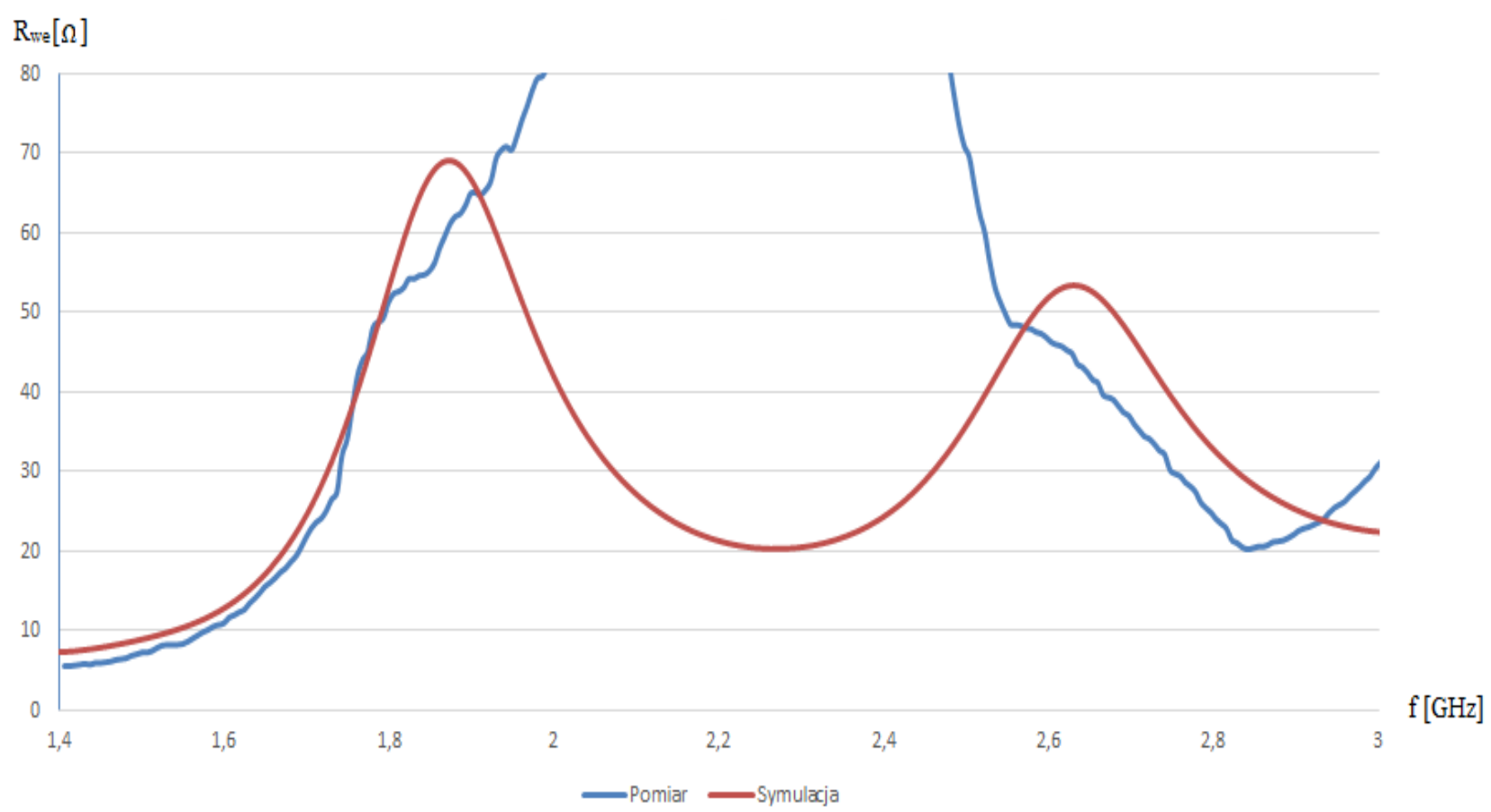

Figure 7. List of characteristics a) WFS b) reactance c) resistance of the antenna physically made and simulated in the CST program.

\section{SUMMARY RESULTS}

Received results physical antenna model research in the Electromagnetic Compatibility Laboratory slightly differ from those obtained during computer simulation in the CST Studio Suite environment. The laminate that was used to create the antenna was a substrate of the low quality. Choose of the substrate is very important on the stage of antenna design. For example we can find at ROGERS catalog materials, that the dielectric thickness tolerance for the majority of produced laminates is up to $\pm 7 \%$, and for the FR-4 laminate family up to $\pm 15 \% .{ }^{4,8}$

The antenna was designed in the CST Studio environment on the substrate FR - 4 with a dielectric constant $\varepsilon_{\mathrm{r}}=4.6$. The dielectric constant $\varepsilon_{\mathrm{r}}$ of most FR-4 laminate family can vary $\pm 10 \%$ or more. ${ }^{8}$

The research the impact of antenna dielectric thickness on selected parameters showed that a change in thickness even of $0.1 \mathrm{~mm}$ causes a change in bandwidth, gain or impedance. The change in dielectric constant $\varepsilon_{\mathrm{r}}$ has a similar effect.

The bands obtained in the laboratory almost completely overlap with the bands supported by LTE and GSM technology. Moreover the dielectric thickness significantly influence on selected antenna parameters.

\section{REFERENCES}

[1] Bugaj, J., Bugaj., M., "Analyze the impact of discretization on the structure of the simulation result," PIERS Proceedings, 287-291, 2015.

[2] Balanis C.: "Antenna Theory, " 4-rd Ed, Wiley, 2016.

[3] Kubacki, R., Czyzewski, M., Laskowski, D. "Microstrip antennas based on fractal geometries for UWB application," MIKON 2018 - 22nd International Microwave and Radar Conference pp. 352-356, 2018 Bugaj, J., 
[4] Łata, K., "Analiza numeryczna wpływu grubości dielektryka na wybrane parametry i charakterystyki zaprojektowanej anteny LTE," Elektronika: konstrukcje, technologie, zastosowania 59 (8), 2018.

[5] Kubacki, R., Lamari, S., Rudyk, K., "The microstrip antenna with periodic planar pattern," 2016 Progress In Electromagnetics Research Symposium, PIERS 2016 - Proceedings 7734576, pp. 1050-1054, 2016

[6] Kelner, J.M., Ziolkowski, C., Nowosielski, L, "Angular Dispersion Modelling for 5G Wireless Link with Directional Antennas," 22nd International Conference Electronics, ELECTRONICS 2018

[7] Wnuk, M., Nowosielski, L., "Car microstrip GPS antenna," Progress in Electromagnetics Research Symposium 2017-November, pp. 444-448

[8] https://www.rogerscorp.com/documents/2122/acm/articles/Understanding-When-To-Use-FR-4-Or-High-FrequencyLaminates.pdf 